\title{
Epidemiology of large bowel disease: the role of fibre
}

\author{
By D. P. BurkitT, Medical Research Council, I72 Tottenham Court Road, London \\ $W_{\mathrm{I}} P{ }_{9} L G$
}

\begin{abstract}
Incidence of non-infective disease of the large intestine in western Europe and North America
\end{abstract}

Appendicitis is the commonest abdominal emergency and it has been estimated that nearly one in ten of the population have had their appendixes removed. Diverticular disease is the commonest pathological condition of the large bowel, possibly affecting half of the population over the age of 60 years.

Carcinoma of the colon and rectum is responsible for more deaths than any form of cancer except that of the lung.

Benign tumours of the rectum are present in nearly one-quarter of the adult population.

\section{Emergence as clinical problems in American whites and negroes}

Appendicitis was rare before the turn of the century, then the incidence increased steeply until about the time of the second world war.

Diverticular disease was a relative curiosity until after the first world war. It became increasingly common over approximately the next 30 years to reach its present endemic proportions. There is no available evidence to indicate when cancer of the bowel became an important health problem.

Forty years ago the incidence of all these diseases was much lower in the negro than in the white population. This disparity has now almost disappeared.

\section{Present situation and changing patterns in developing countries}

In contrast with the above situation these non-infective diseases of the large bowel are rare in developing countries. Appendicitis is very uncommon throughout rural Africa and has only a slightly greater incidence in village communities in India and Pakistan (Burkitt, r97 Ia). Diverticular disease is almost unknown in these countries, even in urban communities (Painter \& Burkitt, 197I). Bowel cancer, which is more closely related to economic development than any other form of cancer, has its lowest incidence in areas such as rural Africa (Doll, 1969; Burkitt, $\mathrm{I} 97 \mathrm{I} b$ ). Benign bowel tumours are rare or unknown among people who have deviated little from traditional patterns of life. 


\section{Changes on urbanization and westernization}

In developing countries appendicitis is much more prevalent in urban than in rural communities and in the upper rather than in the lower socio-economic groups. So evident is this in East Africa that it has frequently been said that only those who speak English develop appendicitis. Hallilay ( 1924 ) cited many examples of the rare incidence of appendicitis in Indians with the exception of members of the upper classes who had adopted many Western customs. Similar experience has been recorded from other areas and these have been fully substantiated by regulat reports giving particulars of this and other diseases sent to me from over 150 hospitals in developing countries.

Diverticular disease is appearing in the upper socio-economic groups in countries like India and Iran, but even in large cities only occasional cases are yet seen in Africa.

Bowel cancer in India, though rare by comparison with the Western world, is more prevalent than it is in Africa where there is some evidence that the incidence is beginning to rise in some of the larger cities.

\section{Changes on emigration}

All non-infective diseases of the large bowel are much more common in Japanese who have been born in Hawaii than amongst those living in Japan (Stemmermann, 1970).

Interrelationship between the non-infective diseases of the large bowel

The different non-infective diseases of the large bowel are closely related to onc another in their geographical distribution and in their time of emergence in different communities. They all have their highest incidence in most Westernized countries and their lowest among peoples living in a traditional manner. With the exception of appendicitis, which becomes common several decades before the other diseases, they appear to emerge as clinical problems at about the same time in different situations. These observations suggest that there may be some causative factor common to each.

\section{Environmental dependence}

The epidemiological evidence indicates that environmental rather than genetic factors must be responsible for the variations in prevalence of each of these diseases both geographically and chronologically. This poses the question 'what environment?".

The most important environmental factor likely to influence bowel behaviour and mucosal changes is the faecal content. This is largely dependent on the food eaten and, in the instance of the large bowel particularly, the fraction of food not digested in the small intestine. It is therefore pertinent to examine changes in diet which, in different situations, preceded, by a relatively short period, an increase in the 
incidence of appendicitis and, by a longer period, the appearance of the other diseases as common medical conditions.

\section{Food changes preceding an increased prevalence in these bowel diseases}

Both in the Western world and in developing countries major food changes which preceded a rapid increase in the incidence of appendicitis in certain communities have been an increased consumption of fat, protein and sugar and a reduced intake of unabsorbable fibre.

It is therefore important to consider the effects of these dietary changes on bowel behaviour and content and then to relate these to possible pathological changes.

\section{Changes in bowel behaviour and content related to diet}

The relationship between dietary fibre and bowel behaviour and content has been well documented (Walker, 1947, 1961; Burkitt, Walker \& Painter, I972). Diets with a high fibre content are associated with rapid intestinal transit times, 25-40 h, and large soft motions with mean stool weights often greater than $300 \mathrm{~g} / \mathrm{d}$. In contrast, communities on low-residue diets, typified by modern foods of western Europe and North America, have mean intestinal transit times greater than $70 \mathrm{~h}$ and which are commonly greater than $4 \mathrm{~d}$. Stools are characteristically firm, small and often faceted, and mean daily stool weight is 100-1 $50 \mathrm{~g}$. Intestinal transit times and stool weights in communities on a mixed diet are between these extremes.

It has been observed that the addition of as little as $2 \mathrm{~g}$ of cereal fibre/d to Western diets restores normal bowel function in most people, with the result that stools are firm and transit times are prolonged. This is further evidence that fibre is an important factor in maintaining normal bowel behaviour. There is no evidence that fat or protein significantly change bowel motility.

Aries, Crowther, Drasar, Hill \& Williams (1969) and Hill, Crowther, Drasar, Hawksworth, Aries \& Williams (1971) have shown that Western diets are associated with bacterial flora which differ from those in traditional diets of developing countries. It was suggested that these differences could have been mainly the result of changes in fat consumption. It is equally possible that changes in dietary fibre may determine the pattern of bacterial flora since pentosans, an important component of fibre, are largely broken down by bacteria in the large bowel.

\section{Relating disease to bowel changes resultant on fibre-depleted diets}

(a) Constipation. This is an important problem in economically-developed countries. The main cause of constipation is now believed to be the lack of dietary fibre and, consequently, the most important prophylactic or therapeutic measure is the return of fibre to the diet (Avery Jones, 1972).

(b) Appendicitis. This is believed to result from obstruction of the lumen of the appendix either by a concretion of firm faeces (faecalith) or by muscular contraction; both these are the result of fibre-depleted faeces (Short, 1920; Burkitt, 1971a). 
Changes in the faecal flora may also be an important factor (Cleave, Campbell \& Painter, 1969).

(c) Diverticular disease. This is now widely accepted as being the direct result of a low-residue diet. When unnaturally strong muscle contractions try to propel the firm faecal masses along the colon pressures are built up within its lumen. 'These pressures blow out the diverticula (Painter, I964, 1970). Unfortunately it was formerly believed that a high-roughage diet irritated the colon and consequently a low-fibre diet was prescribed for the treatment of this condition. Now that a lowfibre diet is known to be the cause of the disease, a high-fibre diet is becoming the standard treatment.

(d) Tumours. Benign and malignant tumours probably result from the same or similar causes (Morson \& Bussey, 1970). It is believed that the faecal bacteria which are characteristic of communities having a high risk of developing bowel cancer degrade bile salts or other faecal constituents and form potential carcinogens (Aries et al. 1969; Hill et al. 197I). On a low-fibre diet any carcinogens formed would be held in contact with the bowel mucosa for a prolonged time, concentrated in a small faecal volume. Also, the faecal arrest which is the consequence of a fibre-depleted diet would provide more time for proliferation of bacteria and for their action on bile acids. Each of these effects might increase the chance of developing cancer or benign tumours (Wynder \& Shigematsu, r967; Burkitt, r971 $b$ ).

\section{Epidemiological associations between non-infective diseases of the bowel and some other diseases}

Not only are the non-infective diseases of the bowel related to one another, but they are also associated with certain other diseases which are similarly characteristic of modern Western civilization. These include venous disorders such as varicose veins, deep-vein thrombosis and haemorrhoids, which have been attributed to unnaturally increased intra-abdominal pressures caused by straining at firm stools (Burkitt, 1972).

Other non-infective diseases include those related to changes in small-bowel absorption with consequent derangement of cholesterol and bile-acid metabolism. The most important of these are cholesterol gallstones and ischaemic heart disease which will be discussed in the next paper.

\section{Conclusions}

There is good evidence that a fibre-deficient diet plays an important causative role in some common and serious diseases. Restoring fibre to the diet would go far in counteracting the possible ill-effects of constipation outlined above. Since it has been shown that the passage of meals of wholemeal bread through both the small and large bowel is considerably quicker than those composed of white bread (McCance, Prior \& Widdowson, 1953), an increased consumption of bread of a high extraction rate would seem a good and perhaps the best way of restoring some degree of normality to bowel behaviour in affluent communities. An alternative or 
additional approach would be the supplementation of our food with I-4 dessertspoonfuls of unprocessed bran/d.

\section{REFERENCES}

Aries, V., Crowther, J. S., Drasar, B. S., Hill, M. J. \& Williams, R. E. O. (1969). F. Br. Soc. Gastroenterology 10, 334 .

Avery Jones, F. (1972). In Management of Constipation. p. 97 [F. Avery Jones and E. W. Godding, editors]. Oxford: Blackwell Scientific Publications.

Burkitt, D. P. (1971a). Br. F. Surg, 58,695.

Burkitt, D. P. (1971b). Cancer, Lond. 28,3 .

Burkitt, D. P. (I 972). Br. med. F. 2, 556 .

Burkitt, D. P., Walker, A. R. P. \& Painter, N. S. (1972). Lancet ii, I408.

Cleave, T. L., Campbell, G. C. \& Painter, N. S. (1969). Diabetes, Coronary Thrombosis and the Saccharine Disease and ed. Bristol: John Wright \& Sons Itt.

Doll, R. (1969). Br. F. Cancer 23, r.

Hallilay, H. (1924). Indian med. Gaz. 59, 403.

Hill, M. J., Crowther, J. S., Drasar, B. S., Hawksworth, G., Aries, V. \& Williams, R. E. O. (I97I). Lancet i, 95 .

McCance, R. A., Prior, K. M. \& Widdowson, E. M. (1953). Br. F. Nutr. 7, 98.

Morson, B. C. \& Bussey, H. J. R. (1970). Predisposing Causes of Intestinal Cancer : Current Problems in Surgery. Chicago: Year Book Medical Publishers Inc.

Painter, N. S. (1964). Ann. R. Coll. Surg. 34, 98.

Painter, N. S. (1970). Proc. R. Soc. Med. 63, Suppl. 144.

Painter, N. S. \& Burkitt, D. P. (1971). Br. med. F. 2, $45^{\circ}$.

Short, A. R. (1920). Br, F. Surg. 8, г71.

Stemmermann, G. N. (1970). Archs envir. Hith 20, 266.

Walker, A. R. P. (1947). S. Afr. med. F. 21, 590.

Walker, A. R. P. (196I). S. Afr. med. F. 35, I 14.

Wynder, E. L. \& Shigematsu, T. (1967). Cancer, Lond. 20, 1520. 